\title{
NOVA CARTOGRAFIA SOCIAL: EXPERIÊNCIAS METODOLÓGICAS E REPERTÓRIO CONFRONTACIONAL NO NORDESTE DO BRASIL
}

\author{
NEW SOCIAL CARTOGRAPHY: \\ METHODOLOGICAL EXPERIENCES \\ AND CONFRONTATIONAL \\ REPERTOIRE IN THE NORTHEAST OF \\ $B R A Z I L$
}

\section{Rita de Cássia M. Neves}

rcmneves@yahoo.com.br

Professora adjunta do DAN/PPGAS UFRN

Vânia Fialho

vania.antropologia@gmail.com

PROCADI/UPE PPGA/UFPE

Doutora em Sociologia pela UFPE

\section{RESUMO}

A ocupação do solo e o estabelecimento de novas territorialidades sempre foram elementos de disputas em que se destacam as lógicas coloniais perpetuadas através das desigualdades de direitos e da imposição de uma lógica de comoditização da terra. Neste trabalho, a partir da experiência do Projeto Nova Cartografia Social no Nordeste brasileiro, discutiremos tanto aspectos metodológicos das pesquisas, que tiveram como ponto fulcral a elaboração de mapas no contexto etnográfico e suas implicações para diferentes esferas do exercício do poder, quanto as disputas vivenciadas por comunidades urbanas e rurais no nordeste do Brasil contemporâneo, pautadas no entendimento de que isso possibilita um processo reflexivo nos próprios grupos sociais envolvidos. As pesquisas têm como experiência as potencialidades e disputas políticas territoriais na comunidade quilombola de Conceição das Crioulas-PE, no Povo indígena Xukuru do Ororubá-PE e Tapuias da Lagoa de Tapará-RN, e as e disputas urbanas no bairro de Santo Amaro, Recife-PE.

Palavras-Chave: Nova Cartografia Social. Mapas. Ação Política.

\begin{abstract}
The occupation of land and the establishment of new territorialities have always been elements of disputes in which the colonial logics perpetuated by the inequalities of rights and the imposition of a commoditization logic of the land stand out. In this work, based on the experience of the New Social Cartography Project in the Brazilian Northeast, we will discuss the methodological aspects of the research, which focused on the elaboration of maps in the ethnographic context and their implications for different spheres of the exercise of power; as well as the disputes experienced by urban and
\end{abstract}


rural communities in northeastern Brazil, based on the understanding that this leads to a reflexive process in the social groups involved. The researches have as an experience the territorial political potentialities and disputes involving quilombola community of Conceição das Crioulas-PE, two indigenous people Xukuru do Ororubá-PE and Tapuias da Lagoa de Tapará-RN, and the urban disputes in the neighborhood of Santo Amaro, Recife PE.

Keywords: New Social Cartography. Maps. Political Action.

\section{A EXPERIÊNCIA DO "PROJETO NOVA CARTOGRAFIA SOCIAL" NO NORDESTE}

O objetivo deste artigo é discutir e problematizar os aspectos metodológicos de duas pesquisas multidisciplinares e suas implicações para diferentes esferas do exercício do poder ${ }^{1} \mathrm{o}$ que possibilitou uma maior compreensão das questões sociais urbanas e rurais que associam as unidades de mobilização às motivações de cunho identitário. Trata-se, portanto, de uma proposta que se apropria da categoria "espaço" para identificar os conflitos, os lugares de socialização, bem como a relação entre configuração espacial e identidade.Para além desses aspectos, intencionamos colocar em evidência como a apropriação da técnica, no caso a cartográfica, pode possibilitar a elaboração de um repertório de ação coletiva que desestabiliza relações de dominação historicamente constituídas.

Usaremos como base etnográfica de discussão, a experiência do Projeto Nova Cartografia Social em quatro comunidades, cujos objetivos e contextos são extremamente distintos, mas que através de processos também distintos nos dão uma visão ampla das metodologias e objetivos do trabalho desenvolvido. Esse artigo aborda as experiências na comunidade urbana de Santo Amaro, na Comunidade Quilombola de Conceição das Crioulas, no Povo Indígena Xukuru do Ororubá, no Estado de Pernambuco e no Povo Indígena Tapuias da Lagoa de Tapará, no Estado do Rio Grande do Norte, Brasil.

De forma genérica, a proposta inicial dos projetos do Nova Cartografia Social é discutir o potencial de mobilização social possibilitando subsidiar futuras intervenções em políticas públicas pautadas nas realidades dos movimentos sociais com os quais trabalhamos. Diante do problema do estigma e do insucesso de políticas públicas na maioria das comunidades, o Projeto Nova Cartografia Socialpossibilitou visualizar o potencial de mobilização e identificar as ações que vêm sendo efetivadas para suplantar o preconceito que recai sobre essas populações e lidar com os problemas estruturais que enfrentam no cotidiano. Apesar dessa característica mais geral, cada trabalho cartográfico tem sua especificidade e responde a propósitos diferenciados, como veremos mais à frente quando analisarmos esses trabalhos.

É importante ressaltar que as pesquisas que originaram esse texto nasceram da articulação com o Projeto Nova Cartografia Social (PNCS), coordenado pelo Professor Alfredo Wagner Berno de Almeida e inicialmente sediado na Universidade Estadual do Amazonas (UEA). O PNCS objetiva a produção de mapas elaborados pelos segmentos sociais envolvidos. Com uma metodologia participativa que estimula a atuação das comunidades, o PNCSpretende levantar todos os tipos de problemas que assolam determinada área, assim como também identificar as potencialidades locais. Ao tratar também das emergências de identidades coletivas, o PNCS tem dado visibilidade às práticas jurídicas e mostrado as dificuldades desses povos junto ao poder público. Além disso, dá visibilidade a diferentes formas de ação coletiva que possibilitam identificarmos estratégias políticas criativas na conformação das disputas contemporâneas. 
Podemos dizer que a experiência do PNCS pode ser compreendida como um dos elementos que Charles Tilly (ALONSO, 2012) definiu como "repertório (político) confrontacional", no sentido que reconstrói o contexto político ou a estrutura de oportunidades e ameaças políticas, possibilitando que grupos sociais historicamente invisibilizados pudessem enfrentar o poder de autoridades e forças antagônicas.

Ao expandir a proposta do PNCS para a região Nordeste do Brasil ${ }^{2}$, houve incialmente uma articulação de um grupo de pesquisadores no Estado da Bahia, formando uma frente de trabalho e, logo em seguida, outro grupo de pesquisadores também se articulou e passou a atuar na região, mais especificamente nos Estados de Pernambuco, Paraíba e Rio Grande do Norte, no qual esse trabalho se insere, formando uma outra frente.

No caso das pesquisas em Pernambuco, foram realizadas oficinas de mapas, que consistem em reuniões livres, abertas a toda comunidade, em que se discutiram temas importantes sobre a realidade local. Através de trabalho de campo etnográfico realizado anteriormente ao projeto, como no caso do quilombo de Conceição das Crioulas e dos índios Xukuru, ou realizado durante o próprio processo da cartografia social, caso da comunidade urbana de Santo Amaro.

O trabalho na comunidade indígena Tapuias da Lagoa de Tapará, no Rio Grande do Norte, por sua vez, teve início a partir de um contato com as lideranças na II Assembleia Indígena do RN, em 2011, em Goianinha-RN. No entanto, apenas em 2015 iniciamos efetivamente as atividades do PNCS nessa comunidade, através do grupo Motyrum (Nucleo Indígena) de ações extensionistas da UFRN. Vale salientar que o Projeto Nova Cartografia Social havia sido apresentado durante a Assembleia por Rita Neves (UFRN) e Hosana Santos (UFPE) a pedido dos organizadores da assembleia. Na ocasião, as mulheres de Tapará que estavam presentes nos convidaram para conhecer a comunidade. No entanto elas tinham como objetivo ajuda para organização da I Feira de Cultura dos indígenas da Lagoa de Tapará. Essa era a demanda e a intensão do grupo e embora nosso interesse fosse a cartografia, levamos um ano inteiro de trabalho e só após a feira de cultura nos convidaram a realizar a cartografia.

\section{MAPAS E GUERRAS SIMBÓLICAS}

O campo teórico no qual esse artigo está ancorado parte do pressuposto de que "todos os mapas são uma abstração do mundo, elaborada sempre a partir de um ponto de vista". (ASCERALD; COLI, 2008, p. 10). Dessa forma compreendemos que os mapas são instrumentos posicionados e sempre foram usados dessa forma. A questão que nos interessa é que por apresentarem a posição de quem detém o poder instituído, o que no caso presente se configura como o Estado Nação, seu método e formato, sempre serviu como instrumento de dominação e controle territorial. Ao tratar da relação entre tecnologia e poder a partir da obra de Feeberg, Neder (2010) afirma que "os senhores dos sistemas técnicos são responsáveis pelas decisões que obscurecem, distorcem ou filtram, e mesmo regulam diretamente a aplicação das decisões tomadas sob o estado de direito da democracia política. (NEEDER, 2010, p. 18). No entanto, as experiências que relatamos neste artigo problematizam a prática cartográfica, que sempre esteve engajada na defesa de uma hegemonia, levando-nos a crer que acabam por subverter as práticas técnicas, os procedimentos, e os arranjos que estruturam a vida cotidiana.Eles sugerem a criação de uma nova esfera pública que inclua o background técnico da vida social, e um estilo novo de racionalização que internalize custos não contabilizados na pretensa neutralidade da técnica. 
Compreendemos também que a representação cartográfica é uma leitura particular da realidade plotada em um mapa, os mapas são uma linguagem de poder, e mais, se configuram como territórios em disputa numa verdadeira guerra simbólica. Vianna (2009) faz referência à «guerra simbólica» de mapas para afirmar a disparidade que existe entre as formas de representação de uma comunidade realizada por agentes externos, geralmente, os "senhores dos sistemas técnicos" (FEENBERG,1992), e aquelas realizadas pelos próprios sujeitos.

Em palestra proferida em 2015, Henri Acserald faz referência à noção de "contraespaço público" da filósofa Nancy Fraser destacando a importância das práticas cartográficas para evidenciar mundos invisibilizados, que designariam "territórios discursivos paralelos em que os integrantes dos grupos sociais subordinados inventam e põem em circulação contradiscursos em oposição às interpretações opostas a suas identidades, interesses e necessidades". (FRASER, 1991, apud ACSERALD, 1997, p. 28).

Em outra publicação, Ascerald juntamente com Luís Régis Coli (2008), ao situarem as várias iniciativas de mapeamento, apontam três principais razões para que possamos entender o crescente interesse pelo campo da cartografia associado às mais diferentes áreas de conhecimento:

$1^{\circ}$ ) a maior parte das informações utilizadas na formulação de políticas, seja referente à criminalidade, planejamento de uso do solo, saúde ambiental, conservação de habitat ou provisão de serviços sociais contém um componente espacial; $2^{\circ}$ ) a ampliação do uso de informações espaciais para todas as partes interessadas leva presumivelmente a uma melhor formulação de políticas; $3^{\circ}$ ) estas informações politicamente relacionadas podem ser analisadas e visualizadas espacialmente, e o produto resultante - em sua maioria, mapas - pode transmitir ideias de forma persuasiva e convencer as pessoas da importância destas ideias. (ASCERALD; COLI 2008, p. 18-19).

Nossa opção foi a de adotar a perspectiva da "cartografia social". (ALMEIDA, 1993). Nesta, o processo de inclusão dos grupos envolvidos é de especial interesse, partindo do pressuposto de que os sujeitos sociais são capazes de se familiarizar com a ideia do mapa e com o repertório de informação nele contido.

Com essa análise procuramos compreender que movimentos sociais, unidades de mobilização, territoriais e de identidades estão presentes e de que maneira esses, juntos a outros dispositivos (legais, institucionais e discursivos), se articulam-se à vida cotidiana e se projetam espacialmente.

Os mapas resultantes das oficinas de cartografia social que foram realizados no percurso dos projetos - sejam de pesquisa ou extensão universitária - tomaram o lugar como uma categoria importante, "cujo sentido tem se firmado, no plano conceitual, a partir da década de 1970 como um espaço percebido sentidos de lugar e as imagens de lugar, envolvendo a dimensão cultural-simbólica". (SOUZA, 2013, p.16-17).

O local, que tomamos aqui como sinônimo de espaço, é sempre tratado como objeto real, que se impõe a nós, por seu caráter natural, por sua necessidade antropológica ou cognitiva, por sua duração (Bourdin, 2001). No entanto, reconhecendo outra possibilidade posta pelo mesmo autor, adotamos o espaço como categoria de análise, através da qual podemos procurar a compreensão para questões presentes na sociedade. Consideramos, assim, o espaço e a possibilidade de definir seus limites relacionando-o às identidades e à coesão afetiva, ética e política dos grupos, «num jogo da diferença, que garante uma harmonia ao mesmo tempo em que relativiza o poder». (BARCELLOS, 1995). 
Esse trabalho, portanto, parte do pressuposto de que os espaços físicos constituem lócus de socialização e que o olhar cuidadoso sobre ele, a partir de um instrumental teórico e metodológico diversificado, pode dar visibilidade a aspectos ainda não percebidos das relações sociais.

\section{CONFLITOS E DISPUTAS TERRITORIAIS NO NORDESTE}

O Nordeste do Brasil é uma região de contrates, considerada por uns como uma região atrasada. Nos últimos dez anos vêm passando porum intenso processo de desenvolvimento econômico, inclusive acima da média nacional. $\mathrm{O}$ que se pode observar através dos dados oficiais é que o padrão de crescimento iniciado durante o governo Lula beneficiou a região Nordeste. A região atingiu $13,5 \%$ de participação no PIB nacional, o maior porcentual da série histórica iniciada em 1995 pelo Instituto Brasileiro de Geografia e Estatística (IBGE). O avanço dos Estados nordestinos entre 2002 e 2010 foi de 0,5 ponto porcentual, menor apenas que o ganho da Região Norte, de 0,6 ponto porcentual, conforme foi veiculado pelo jornal O Estado de S. Paulo em 23.09.2913.

De acordo com a socióloga Tânia Bacelar, em conferência regional sobre Determinantes Sociais em Saúde ocorrida no ano de 2013, na cidade de Recife, o Nordeste do Brasil teve um aumento de renda média nos últimos 10 anos, bem maior que as regiões Sul e Sudeste no mesmo período. Além da renda, houve em consequência um aumento no consumo, o que provocou um aumento do número de empresas que passaram a se instalar na região.

O problema, ainda de acordo com Bacelar, é que ao mesmo tempo em que a região observou um desenvolvimento acelerado, alguns entraves permanecem como uma "máquina de gerar desigualdades": O sistema tributário não foi alterado. Nesse caso, o problema não é o tamanho da carga tributária, mas quem a paga; ainda se observa uma concentração fundiária tanto na área rural quanto urbana. Na educação, os dados apontam um ensino fundamental de baixa qualidade; o investimento em Ciência e Tecnologia é muito pequeno no Nordeste, em relação ao Sul e ao Sudeste do Brasil.

Fialho (2011), ao analisar o processo desenvolvimentista que ocorreu no Nordeste nos últimos anos, afirma que o projeto de modernidade que chegou ao Nordeste brasileiro passou a enfrentar problemas quando encontra no caminho outros modelos e contextos distintos, principalmente quando entra em contato com os novos movimentos sociais ou comunidades tradicionais. A autora não coloca em dúvida os benefícios econômicos e infraestruturais para a região, mas a partir de conflitos observados em empreendimentos tais como a transposição do Rio São Francisco, a construção da Ferrovia Transnordestina ou a expansão do Porto de Suape, em Pernambuco, aponta um outro processo que parece ter sido deixado de lado: o reconhecimento dos direitos das comunidades tradicionais ao seu território, bem como os diversos usos que fazem dele.

\footnotetext{
"Os grandes empreendimentos, seja pela ocupação espacial, seja pela exploração de recursos naturais necessários para sua manutenção, ou ainda pela apropriação de determinados conhecimentos, têm encontrado na sua contramão a presença de tais povos e comunidades tradicionais." (Fialho, 2011, p. 155).
}

Com isso, a autora reforça que precisamos refletir sobre o paradoxo que foi estabelecido a partir da constituição de 1988, em que ao mesmo tempo em que o Estado brasileiro se afirma como plural, negligencia as diferentes 
lógicas de relação com a terra e com o entorno. Além disso, as obras de infraestrutura e transformação econômica que são realizadas na região, em sua grande maioria não são realizadas a contento e nem concluídas observando a especificidade e diversidade da população atingida.

Scott (2012), ao analisar o impacto de grandes projetos no Nordeste, como a construção da Barragem de Itaparica, chama atenção para as "táticas de desmonte", relações que se estabelecem entre os grandes empreendedores e os atingidos por esses empreendimentos. Para ele o processo da Barragem de Itaparica apresentou quatro táticas de desmonte, que também podem ser observadas em outros empreendimentos como os citados acima: 1) "desmoralização", em que pouco a pouco a identidade positiva dos assentados vai sendo questionada, sugerindo que os mesmos estão burlando o sistema para conseguir benefícios, em vez de percebê-los como cobrando seus direitos; 2) "metamorfose institucional", em que as mudanças institucionais de negociadores e a diversidade de níveis decisórios acabam permitindo um discurso do descompromisso com promessas anteriores sob a alegação de terem sido feitas por outros; 3) "abandono planejado", em que alegando incompetência em determinada questão mitigadora dos problemas do empreendimento, a empresa responsável transfere a competência para outros o que possibilita um descompromisso com o que havia sido planejado; 4) "incorporação burocrática", em que as organizações representativas dos grupos atingidos após a implementação dos projetos, passam a operar com populações diferentes das inicialmente atingidas, mudando muitas vezes o foco e produzindo uma burocratização do cotidiano da própria organização deslegitimando-as perante a população atingida.

As comunidades tradicionais presentes nessas regiões foram alvo desse processo das diferentes lógicas de uso da terra e encaminharam demandas, principalmente de regularização fundiária a partir ou de uso coletivo da terra ou de propriedades privadas comunitárias, em especial as comunidades indígenas e quilombolas. Esse processo que se configura como de afirmação de identidade e demanda por reconhecimento de direitos territoriais tem na sua base, como afirma Fialho (2011), uma "redefinição da ruralidade brasileira".

\section{O PROBLEMA ÉTNICO TERRITORIAL - COMUNIDADES QUILOMBOLAS E INDÍGENAS}

A questão que permeia toda essa discussão acima é como incluir uma política diferenciada, como indicada na Constituição de 1988, no seio de uma Nação pensada a partir de uma ideologia atrelada ao individualismo? (Direitos coletivos em oposição a direitos individuais). Da perspectiva legal, muita coisa já foi alterada na relação entre os indígenas, os quilombolas e o Estado desde a implantação da Constituição. $O$ respeito à diversidade étnica, embora se faça lentamente, pode ser visto no campo da educação e saúde diferenciada. No entanto, do ponto de vista da autonomia e controle do território indígena e quilombola, principalmente no reconhecimento de organizações sociais diferenciadas, desenvolvem-sereceios de fragmentação e perda de controle pelo Estado. Além disso, nos últimos dois anos, desde 2016, após o impeachment da presidenta eleita Dilma Rousseff, houve intenso movimento em direção ao retrocesso de direitos conquistados na Constituição de 1988. Toda essa discussão pode ser considerada do ponto de vista de uma luta entre uma teoria dos direitos de orientação individualista e o reconhecimento para identidades coletivas ou reconhecimento para formas de vida culturais distintas como afirma Habermas. (2002, p. 230-231). 
Em relação à questão quilombola, Almeida (2011), afirma que passados todos esses anos desde a promulgação da Constituição de 1988, ainda há uma relutância e descaso de sucessivos governos em aplicar o artigo 68 do Adct-Atos das Disposições Constitucionais Transitórias.Constata-se, segundo o autor, a persistência de polêmicas jurídicas, como se as normas determinassem a dinâmica da vida social dos quilombolas. Como resposta a essas discussões, as pessoas passam a se definir como identidades coletivas negras, quilombolas, independente das classificações externas e da discussão que se desenvolve no âmbito jurídico.

Em relação aos povos indígenas, alvos de todos esses processos, a situação não é muito diferente. Quando tratamos da questão de uso e controle do território indígena, os problemas se intensificam. Os questionamentos quanto à identidade étnica, às reais intenções dessa população e, principalmente, ao modelo organizacional das mesmas, surgem acionadas pelas forças políticas tradicionais como forma de negar direitos constitucionalmente reconhecidos. Assim como os quilombolas, as populações indígenas seguem se definindo e em disputa pelo controle do seu território.

\section{DISPUTAS URBANAS}

As discussões sobre as cidades e a ocupação e uso do solo na sociedade atual também constitui uma dimensão que deve ser pensada a partir de uma lógica dos direitos e disputas. Trata-se de perceber a relação das pessoas que vivem nos espaços urbanos e do uso desses espaços na configuração de conflitos e constituição de identidades.

Grande parte da população urbana vive num espaço pouco controlado, pouco visto, pouco conhecido, muito reduzido e precário na sua materialidade. Apesar dessas configurações, as cidades também podem ser vistas como "modelos urbanos que comunicam analogias e contrastes, repulsões e atrações, conflitos e junturas". (CANEVACCI, 2004, p 138).

Caldeira, no livro "Cidade de Muros: crime, segregação e cidadania em São Paulo (2000), afirmava na época, que os direitos políticos não são mais alvo de violência policial e que os principais alvos da violência policial passaram a ser em sua maioria pobres e negros que vivem nas periferias e áreas urbanas. Apesar da conjuntura, hoje, estar bem diferente daquela em que a pesquisa foi realizada, e de não podermos mais afirmar tão categoricamente que os direitos políticos não são alvos de violência policial, o crescimento urbano também tornou mais complexos os problemas das cidades.

Como forma de atuação junto a essas populações, as prefeituras dos municípios em sua grande maioria passaram a dividir a cidade em zonas ou zoneamentos,acabandopor determinar, separar eexcluir a partir das diferenças de classes sociais. As políticas públicas passaram a considerar esses zoneamentos e a partir deles determinar o que cabe e quais políticas devem ser implementadas em cada bairro ou região, independente dos desejos e anseios da população que se viu cada vez mais acuada em espaços político-geográficos pré-determinados. 


\section{AS CARTOGRAFIAS SOCIAIS E SUAS ESPECIFICIDADES NA EXPERIÊNCIA LOCAL}

Diante dessa realidade, os grupos e comunidades urbanas e rurais têm buscado meios de apresentarem suas exigências diante de um Estado cada vez mais indiferente aos seus anseios e especificidades. O PNCStraz uma abordagem política que faz uso dos instrumentos de mapeamento para discutir com os grupos e as comunidades como estes percebem os espaços e as diversas experiências espaciais, dentrodocontexto apresentado acima.

\section{COMUNIDADE QUILOMBOLA DE CONCEIÇÃO DAS CRIOULAS}

O território do quilombo de Conceição das Crioulas tem uma extensão de aproximadamente 18 mil hectares, localizado no II Distrito de Salgueiro, próximo aos municípios de Mirandiba, Carnaubeira da Penha e Belém do São Francisco.

Conceição das Crioulas é um quilombo dos mais conhecidos no Nordeste. A história do quilombo de Conceição das Crioulas é marcada por luta e resistência. Na época em que a cartografia social foi realizada (2007), os moradores do quilombo só tinham acesso livre a cerca de $30 \%$ de todo o território reivindicado.

O recurso financeiro para realização da mesma foi administrado pela Associação de Moradores de Conceição das Crioulas, para realização das oficinas que ocorreram nos dias 17, 18 e 19 de janeiro de 2007, na Casa Comunitária, situada na Vila de Conceição das Crioulas, localizada no município de Salgueiro (PE), a $550 \mathrm{Km}$ de Recife, capital do Estado de Pernambuco.

A população de Conceição das Crioulas está estimada em 3800 habitantes, conforme dados da própria associação (AQCC, 2004), distribuída em 16 núcleos populacionais, denominados 'sítios'. Os sítios estão espalhados pelo território hoje identificado como de "remanescentes de quilombos" e apresentam certa heterogeneidade em relação à concentração populacional, mobilização política e assistência dos órgãos governamentais.

A cartografia de Conceição das Crioulas foi realizada em dois momentos com cerca de 38 participantes diversificados, divididos por gênero e geração. Em um primeiro momento foi realizada uma reunião para sensibilização e definição de responsabilidades, tais como equipes de trabalho, relatoria, etc.

Em seguida foram realizadas discussões em que nos colocamos como facilitadores do processo. Nessa ocasião, foram discutidos o que é ser "quilombola"; o que é ser de Conceição das Crioulas, etc. Após a discussão, o grupo escolheu os temas a serem abordados no fascículo ${ }^{3}$ e o que constaria no mapa da comunidade.

Os temas escolhidos foram: Terra; Pontos Históricos e áreas de conflitos; Infraestrutura; Recursos hídricos; Geração de Renda e Áreas de Trabalho; Desenvolvimento Social e Manifestações Culturais. Cada tema foi debatido e produzido um texto para o fascículo. Em seguida, os participantes foram explorando e conhecendo as cartas cartográficas que existem sobre a região e, em seguida, realizada a elaboração dos mapas a partir dos temas acima definidos. 
Essa foi uma das primeiras experiências com a metodologia da cartografia social nesse grupo de Pernambuco. Para nós, o processo se encerrou quando devolvemos o fascículo pronto ao grupo. Para a comunidade de Conceição das Crioulas, esse foi apenas o começo.

Em outubro de 2012, um conjunto de instituições organizou um evento na cidade de Recife, intitulado "Outros Mapas: cartografia e pesquisa social". A proposta era discutir as experiências da cartografia social. Em uma das mesas, trouxemos um representante da comunidade de Conceição das Crioulas para apresentar a experiência com a cartografia que foi feita por eles. Nossa surpresa não estava apenas no relato da importância do processo e dos resultados, mas no fato de que, após a entrega do fascículo à Associação de Moradores, os seus membros resolveram continuar a experiência por conta própria. Ou seja, construíram os mais diversos mapas que consideraram importantes: Mapa das cercas que impedem acessos, mapa das riquezas do subsolo, mapa dos mananciais de agua, etc. Os quilombolas de Conceição das Crioulas fizeram mais do que compreender o processo e o papel da cartografia social, eles se apoderaram e expandiram-na.

\section{POVO INDÍGENA XUKURU DO ORORUBÁ}

O povo indígena Xukuru do Ororubá, possui uma terra de 27.555 hectares, localizada no município de Pesqueira (PE), a $214 \mathrm{~km}$ de Recife, na Serra do Ororubá, no agreste pernambucano. A população estimada dos Xukuru é de 12 mil pessoas. Com $95 \%$ de seu territóriodesintrusado, esse grupo é reconhecido no cenário do movimento indígena nacional pela forte presença política de suas lideranças.

A cartografia nos Xukuru seguiu a mesma metodologia da Cartografia de Conceição das Crioulas, ou seja, o controle financeiro ficou a cargo da Associação Indígena Xukuru do Ororubá. No entanto, o processo ocorreu em três etapas:

Na primeira etapa a equipe do projeto se reuniu com o conselho de lideranças para apresentar a proposta e elaborar conjuntamente o projeto de execução da cartografia. A proposta incluía pleitear recursos junto a coordenação do PNCS/UFAM para a realização da oficina e publicação do fascículo.

Na segunda etapa realizamos uma pré-oficina, ocasião em que apresentamos o projeto aprovado a todos os membros do conselho de lideranças Xukuru. Na ocasião foi escolhida pelos Xukuru a base cartográfica e o tema principal: As retomadas do território Xukuru.

$\mathrm{Na}$ terceira etapa foi realizada a oficina propriamente dita nos dias 23, 24 e 25 de outubro de 2009, na aldeia São José, Terra Indígena Xukuru do Ororubá. Estavam presentes na oficina, além das lideranças, as professoras indígenas, jovens do "Ponto de Cultura", o pajé e demais membros que estavam presentes desde a primeira retomada do território Xukuru, totalizando 25 participantes.

Após uma discussão mais ampla e apresentação do tema central da cartografia, o grupo decidiu se dividir em pequenos grupos para discutir alguns subtemas que perpassam o tema central:

- Memória do Território Histórico do Povo Xukuru;

- Conquista Territorial: processos de Retomadas do Território Xukuru; 
- O que diferencia o povo Xukuru - elementos culturais;

- Consequências das Retomada - positivas e negativa.

Duas questões nos surpreenderam no processo da cartografia nesse povo. A primeira, no dia das oficinas, quando todos os grupos apresentaram os resultados do trabalho, os Xukuru, após uma intensa discussão do número e caminho percorrido das retomadas se depararam com o número mais alto de retomadas do que imaginavam. Eles acreditavam que o maior número de retomadas havia sido antes da morte do cacique Xicão e também não tinham a dimensão exata do número total até o cacicado de Marcos, seu filho. Ocorreu nitidamente um processo de reflexividade do grupo. Eles olharam, conferiram várias vezes e foram uníssonos em afirmar a tomada de consciência do processo e de como as retomadas projetaram o sentido de etnicidade do grupo.

A segunda questão é que ao entregarmos as cópias do fascículo pronto com o mapa das retomadas e o texto construído por eles, o cacique perguntou quanto custaria para fazer mais cópias. Ele desejava entregar na escola e a cada comissão desde a educação até a saúde para servir como instrumento de luta, como material pedagógico-educativo e de fortalecimento da identidade do grupo. A publicação, segundo o Cacique Marcos é uma memória do processo de luta, conquista e construção do território Xukuru.

O mais significativo na relação dos Xukuru com a elaboração do seus fascículos, foi o uso do mesmo na Corte Interamericana de Direitos Humanos como principal argumento dos advogados que os representavam. Tratou-se de caso singular, considerando que foi a primeira vez que o Estado brasileiro foi levado ao banco dos réuspor um povo indígena-

\section{COMUNIDADE URBANA DE SANTO AMARO}

A cartografia no bairro de Santo Amaro teve um percurso diferente das anteriores. Enquanto a cartografia em Conceição das Crioulas e nos Xukuru ocorreram a partir de solicitação do próprio grupo cartografado, a do bairro de Santo Amaro esteve atrelada a um projeto de pesquisa anterior, aquele financiado pelo CNPq, Conselho Nacional de Desenvolvimento Científico.No caso do bairro de Santo Amaro, havia duas questões importantes anteriores ao processo. A primeira é que esta seria uma cartografia em área urbana, o que dificulta o acesso pelo número de pessoas e grupos que convivem nesse espaço. Era necessário inicialmente fazer uma pesquisa sobre o bairro, seus problemas e potencialidades. Quando trabalhamos com um grupo específico, como quilombolas ou indígenas, o grupo já tem uma identidade mais claramente estabelecida. No entanto, em um bairro, de caráter popular, não há um grupo específico a quem se dirigir, mas uma imensidão de grupos completamente pulverizados, mas inseridos no mesmo contexto de violência e ausência de políticas públicas específicas para atender à comunidade.

Dessa forma, decidimos que primeiramente faríamos uma pesquisa antropológica inicial no bairro. Foram feitos seminários sobre o bairro com especialistas e membros de associações de moradores do bairro; em paralelo, enviamos alguns projetos de Iniciação Científica, objetivando levantar o maior número possível de ações que estavam ocorrendo em Santo Amaro, assim como a identificação de grupos na área. Por fim, enviamos um projeto maior de pesquisa para o órgão de fomento $\mathrm{CNPq}$ e fomos contemplados com o edital Universal. Ao todo foram cerca de três anos, desde o contato inicial até a realização da cartografia propriamente dita. Para o grupo foi interessante e desafiador todo esse processo 
Situado na região central da cidade de Recife, Santo Amaro faz parte do anel central da cidade, definido pelo Atlas de Desenvolvimento Humano da Cidade de Recife (2005) como a área localizada na parte leste da cidade concentrando as principais atividades de negócios, além da função residencial. Compreende o centro histórico da cidade e o centro expandido que, nos últimos anos, com investimento públicos e privados, ampliou-se tanto a oeste da Avenida Agamenon Magalhães, como ao sul, ao longo dos corredores viários dos bairros de Boa Viagem e Imbiribeira.

Santo Amaro é uma região de ocupação antiga da cidade que mescla a presença de comércio, serviços e residências de classe média e de baixa renda, cuja população marginalizada pela falta de acesso a serviços básicos é marcada pelos altos índices de violência urbana que se define como comunidade ou favela. O Instituto Brasileiro de Geografia e Estatística (IBGE, 2010) apresenta na área conhecida de maneira geral como bairro de Santo Amaro, nove aglomerados subnormais, o que nos ajuda a perceber o seu perfil demográfico ${ }^{4}$.

O bairro de Santo Amaro, no ano de 2007, apresentava características socioeconômicas que o colocam e a seus moradores numa das situações sociais mais críticas, apresentando um dos maiores índices de violência dos centros urbanos brasileiros. De acordo com dados do Instituto Brasileiro de Geografia e Estatística (2000) e do Atlas Recifense de Desenvolvimento Humano (2005), os municípios de Recife, Olinda e Jaboatão dos Guararapes somavam, juntas, $76 \%$ do total de homicídios de Pernambuco. Especificamente em Santo Amaro, segundo informações da Secretaria de Defesa Social do Estado Pernambuco, o número de assassinatos de jovens ( 15 a 24 anos) no bairro, nos três anos anteriores, havia aumentado $80 \%$.

No período inicial da pesquisa, optamos por conhecer as unidades de mobilização através de duas estratégias: visitas iniciais e entrevistas. Esta foi a forma de acessarmos as unidades de mobilização já organizadas de maneira institucionalizada: associações de moradores, associações de esporte, lazer e recreação do bairro.

Nos seminários, reuniões, rodas de diálogos, visitas e entrevistas que organizamos e participamos ao logo da pesquisa destacaram-se os movimentos em torno da regularização fundiária, com ênfase para o movimento de mulheres que tem exercido o protagonismo nas negociações com o Governo do Estado que se desdobrou na regularização fundiária da região denominada Ponte do Maduro, que inclui parte do bairro de Santo Amaro e envolve as ZEIS (Zonas Especiais de Interesse Social) Santo Amaro e Ilha do Joaneiro. Porém optamos pelo conceito de unidades de mobilização (ALMEIDA, 2008), por considerar que poderíamos dar mais visibilidade às mobilizações comunitárias que, mesmo não organizadas formalmente, apresentam potencial de articulação dos moradores do bairro Santo Amaro, cujas atividades são perenes: 1) clubes e times de futebol; 2) grupos voltados para a cultura popular: quadrilhas juninas, blocos carnavalescos; 3 ) grupos de atividades econômicas alternativas.

Findo esse processo de pesquisa, no bairro de Santo Amaro, visibilizou-se a elaboração de duas cartografias distintas, sendo uma com o grupo de crianças participantes de um projeto de extensão da Universidade de Pernambuco, e outra com o grupo da associação de clubes de futebol do bairro, importante movimento dentro da comunidade. A articulação com ambos os grupos para a elaboração das cartografias se deu início no ano de 2013 e em 2016 foi entregue o fascículo sobre os times de futebol do Bairro.

Para a cartografia das crianças, foram realizados quatro encontros nos dias em que as crianças estavam presentes na Universidade para as atividades 
do Projeto Santo Amaro. Participaram da cartografia 15 crianças entre 9 e 13 anos de idade. No primeiro momento, as crianças puderam ver algumas representações do bairro de Santo Amaro em diferentes mapas e puderam conhecer o Projeto da Nova Cartografia Social através de fascículos, inclusive com exemplos de cartografias realizadas por crianças na região Norte do Brasil.

As crianças escolheram como tema a ser cartografado a história do bairro em que vivem e a partir disso, localizar os aspectos positivos e negativos presentes no bairro. Após uma introdução aos mapas e ao significado das representações cartográficas, as crianças passaram a trabalhar o que gostariam de expor no mapa do bairro. Em grupos pequenos, listaram e desenharam pontos que julgaram relevantes aparecer: cemitério, campos de futebol, Universidade de Pernambuco e os pontos de venda de drogas.

O quarto e último encontro foi realizado um ano após as oficinas iniciais. As crianças puderam conferir os mapas elaborados e os textos do fascículo. Sugestões e mudanças foram feitas durante o encontro e, além disso, as crianças presentes expuseram no papel os seus desejos para a vida e para o bairro.

A segunda cartografia, resultado dessa pesquisa maior sobre Santo Amaro foi realizada a partir dos Times de Futebol do bairro. Durante a pesquisa de campo, em que nosso olhar estava voltado para a identificação de associações envolvidas com atividades de cultura, lazer e recreação do bairro, nos deparamos com um número significativo de clubes de futebol no bairro, cerca de 31 clubes, que desenvolvem atividades com crianças, adolescentes e adultos. Alguns desses clubes chegam a se destacar por já ter preparado jogadores que vieram a compor equipes profissionais de Pernambuco.

Inegavelmente, há no bairro a predominância das associações relacionadas ao futebol. Estas se mantêm com recursos próprios ou apoio político-partidário, o que em período de eleição passa a constituir um artifício de cooptação de lideranças. Essa prática é reforçada para se conseguir recursos e garantir a condição de uso dos espaços utilizados para as atividades dos clubes/times, pois esses são negligenciados pelo poder público. As praças, os campos de futebol e as quadras praticamente não recebem manutenção, embora salte aos olhos o fato do bairro possuir 31 times de futebol reconhecidos pelas comunidades.

Um aspecto muito interessante é o fato dos clubes de futebol refletirem a espacialidade do bairro organizado em diferentes comunidades. Foi percebido que as comunidades se articulam também em torno dos serviços a elas oferecidos e devido à carência de condições básicas de sobrevivência, grupos organizados em torno do tráfico de drogas controlam determinadas áreas do bairro. Como consequência, parte das tensões vivenciadas entre as comunidades são acirradas nas competições entre alguns times.

O que também percebemos é que os programas de esporte e lazer pouco utilizam o potencial organizativo do bairro. A intervenção do Estado, através do esporte, é pontual e não aproveita as dinâmicas de organização dos clubes de futebol para ampliar outras ações voltadas para a juventude, saúde e educação.

O previsto na metodologia do projeto era:

- Reunir a representação dos times de futebol para apresentar a Cartografia e definir, se fosse interesse deles, uma agenda de trabalho

- Fazer uma reunião preparatória para a oficina da Cartografia;

- Realizar a cartografia em um ou dois dias. 
No processo nos deparamos com as seguintes dificuldades: impossibilidade de reunir todos os times num só local. Esta reunião foi esvaziada. Os presentes decidiram fazer várias reuniões próximas aos clubes, de modo a obter a anuência do maior número possível deles. Foram reuniões preparatórias nas comunidades Campo do Onze, João de Barros, Santa Terezinha e Santo Amato, no total de cinco; e a oficina de elaboração do mapa que se deu em três datas e mesmo assim não foi possível a participação de todos os clubes; Todas as falas da oficina foram gravadas e ficou decidido o que iríamos abordar na cartografia: A história do futebol no bairro de Santo Amaro; O mapeamento dos times de futebol do bairro; Os objetivos dos times de futebol; As dificuldades enfrentadas pelos times na realização do trabalho; O que gostariam de fazer.

Foi resolvido na oficina preliminar, que os clubes e campos de futebol seriam georreferenciados com GPS pela bolsista e colaboradores do projeto de pesquisa da Upe em desenvolvimento no bairro e com o auxílio dos presidentes dos clubes, tornando possível marcar os pontos de localização deste.O mapa elaborado é parte importante da cartografia do futebol do bairro, possibilitando uma visão espacial mais concreta da presença desta atividade. De acordo com os representantes dos clubes, foi importante o trabalho da cartografia pois foi uma oportunidade de rever o trabalho realizado pelos clubes e dar visibilidade ao trabalho que vem sendo desenvolvido por estes, o que certamente ajudará na obtenção de recursos para melhor poder realizar o trabalho, assim como difundir essas informações para a comunidade recifense.

Durante todo o processo, muitas dificuldades foram sentidas por nossa equipe, desde as tentativas de articulação para a realização das oficinas, até o manuseio das ferramentas demandadas para a produção dos mapas. Nas outras cartografias tínhamos um território minimamente definido. Na cartografia de Santo Amaro, o "território" como base cartográfica fica diluído, mas mesmo assim, esse trabalho resultou em material suficiente para que tanto os grupos cartografados, quanto o poder público possam compreender melhor as especificidades e caráter mobilizador do bairro.

\section{POVO INDÍGENA TAPUIAS DA LAGOA DE TAPARÁ-RN}

O processo de emergência étnica dos índios da Lagoa de Tapará é bem recente. Embora tenham consciência de sua origem indígena, apenas se apresentaram publicamente como índios da Lagoa de Tapará na II Assembleia Indígena do Rio Grande do Norte, que aconteceu na cidade de Goianinha-RN, nos dias 22 a 23 de novembro de 2011. Esse foi um importante espaço para se colocarem como um grupo étnico diferenciado e apontarem algumas reivindicações, inclusive uma presença mais próxima da FUNAI, Fundação Nacional do Índio.

Com uma população de 377 indígenas (dados da comunidade de 2016), habitam a zona rural de dois municípios do Estado: Macaíba e São Gonçalo do Amarante, com biomas da caatinga e da Mata Atlântica, com o Rio Potengi à margem, um açude e uma lagoa.

Segundo as narrativas locais, a população da Lagoa do Tapará descende dos chamados índios Tapuias, que habitavam as matas da região e viviam da caça, da pesca e da agricultura. Outros afirmam que os "caboclos" habitavam toda a região de Tapará. As narrativas sobre a descendência indígena se repetem, como por exemplo, a fala da líder indígena Francisca Bezerra que nos informou ter ouvido de seu pai, que a sua bisavó era uma "índia brava", que foi "pega na mata a casco de cavalo" pelo seu bisavô, homem branco, tendo sido "amansada" 
e "domesticada" para tornar-se esposa. A expressão faz analogia à prática da caça, de modo que associa a caça aos Tapuias como a um "bicho do mato".

A memória dos Tapuias vistos como bravos, fortes, rudes, feios, bichos do mato e outras caracterizações pejorativas, aparece repetidamente na fala das pessoas. Ainda segundo Francisca Bezerra, durante muito tempo negou-se essa origem por medo ou vergonha, pois vigorava o discurso de que não se podia dizer que ali existiam índios para não serem caçados e presos. A mesma lembra que quando criança, na escola, o professor afirmava: "Vocês são todos descendentes de indígenas, mas não podem sair por aí afirmando isso, porque é perigoso".

As melhores terras estão na mão de poucos proprietários e recentemente a área vem sofrendo por conta do desmatamento intenso dessas terras para loteamento e para plantio da cana de açúcar, destruindo o que ainda resta de fauna e flora nativa. A comunidade vem denunciando sistematicamente esse problema de destruição de mata atlântica nativa. Ainda nesse processo, contribui para a degradação da região, a não coleta de lixo, o que faz com que os moradores tenham que queimar os resíduos, contaminando o lençol freático.

Em Macaíba, alguns moradores de Tapará trabalham no comércio ou no serviço doméstico. Em São Gonçalo do Amarante encontramos algumas fábricas de cerâmica que em épocas passadas usavam o barro da lagoa para produção de vasos. No entanto, em todas as casas que visitamos encontramos boa parte dos jovens e adultos em idade de trabalhar, desempregados, vivendo apenas com o dinheiro das aposentadorias dos pais, dos programas assistenciais ou trabalhando nas próprias terras para consumo próprio, sem nenhuma fonte de renda extra.

Ao conversar com as famílias que se apresentam como indígenas, a memória se estende apenas aos pais e avós. Ao perguntar aos mais velhos onde eles nasceram ou de onde vieram seus pais, avós, nenhum afirma ter nascido em Tapará, mas que com chegada dos fazendeiros onde moravam anteriormente, acabaram sendo obrigados a se mudar para onde habitam hoje. Identificamos que, na verdade, os lugares de onde afirmam migrar, são todos no entorno de Tapará.

Nessa etnia realizamos atividades de extensão universitárias, com financiamento da UFRN, bem como realizamos pesquisas em profundidade, financiada pelo CNPq, no edital de Ciências Sociais, atuando durante o ano de 2014 e 2015. Havíamos estado em Tapará no ano de 2013, porém devido às dificuldades de financiamento e da própria comunidade, só retomamos o contato com a comunidade indígena de Tapará em 11 de outubro de 2014. Na ocasião eles nos afirmaram que desejavam realizar um evento que mostrasse para os municípios circunvizinhos que em Tapará havia índios. Por isso queriam realizar em 2015 uma Feira de Cultura. Para isso, precisavam de ajuda pois precisavam realizar um processo de formação e preparação da feira. Dissemos que muitas das coisas solicitadas não estavam ao nosso alcance e algumas não era nosso papel, mas que poderíamos coloca-los em contato com especialistas que pudessem ajudar a realizar algumas oficinas preparatórias para a Feira de Cultura. Na ocasião, aproveitamos esses momentos das oficinas para estar mais próximos ao grupo e realizar a pesquisa com gravação de vídeos e entrevistas semiestruturadas na comunidade, o que foi feito.

Como resultado desse processo acima descrito, os indígenas da Lagoa de Tapará realizaram a primeira feira de cultura em 31/05/2015. Uma camisa com a estampa do cartaz da feira indígena era parte dos itens à venda na feira $\mathrm{e}$ foi o fardamento utilizado pela organização do evento que ocorreu plenamente 
em meio a sol e chuva. Duas tendas enormes e 24 barracas foram montadas em frente ao conselho comunitário com os produtos a serem vendidos: frutas e legumes orgânicos cultivados na comunidade, artesanatos (bonecas de pano, vassouras recicláveis de garrafa plástica, pulseiras, brincos, maracás, esculturas de quengas de coco), folheto de cordel (feito pela comunidade na oficina de poesia) refeições, sobremesas e especiarias, etc. Além disso, dentro da sede foi colocado nas paredes as fotos tiradas pelos indígenas na oficina de fotografia. Por fim, vários discursos foram proferidos pelos indígenas sobre a presença destes no Estado do Rio Grande do Norte, bem como sobre as dificuldades pelo qual passam a comunidade de Tapará para terem sua identidade reconhecida. Por fim, a $1^{\text {a }}$ Feira Cultural de Tapará entrou para o calendário de festas indígenas do RN. Festas essas que tem um importante papel dentro da mobilização indentitária como tivera as assembleias indígenas na década de 1970 nos demais povos indígenas no Nordeste.

Em continuidade ao trabalho realizado para a feira de cultura, após a mesma, nos reunimos com a comunidade para avaliar o processo e, nessa ocasião, nos foi solicitado que facilitássemos o processo da Cartografia Social com a produção de mapas cartográficos e a confecção do fascículo, resultado do processo.

Para iniciar o processo, realizamos um encontro inicial com a comunidade em 23 de agosto de 2015, com 24 pessoas presentes, ocasião em que foi escolhido o tema da cartografia e que refletiu as necessidades dos Tapuias de Tapará: "Reconhecimento do povo indígena da lagoa de Tapará: Ambiente, Cultura e Origens". Ficou acordado também que antes da oficina de mapas e de produção textual, faríamos três oficinas para discutir o tema da cartografia em profundidade. Dessa forma, foram realizadas cincooficinas temáticas que resultaram no fascículo final, com dois grandes mapas: um representativo das origens e migração do grupo e outro referente aos conflitos ambientais e a cultura em que estão inseridos.

\section{PARA ONDE APONTA A CARTOGRAFIA A PARTIR DESSAS EXPERIÊNCIAS?}

Como podemos perceber, a partir de todos esses relatos, é que as experiências do Projeto Nova Cartografia Social têm nos desafiado pela diversidade de modelos, formas e metodologias. Uma das questões que sempre discutimos quando iniciamos um processo ou quando nos encontramos em eventos específicos para pensar em termos teóricos o que estamos fazendo, é como um projeto com caráter metodológico tão diverso pode ser tratado analiticamente?

De fato, a metodologia é muito fluida. A única garantia que buscamos ter é a de assegurar o caráter participativo da mesma. O que vai ser cartografado, de que forma e com que objetivos fica a cargo do grupo. $\mathrm{O}$ nosso núcleo atua como facilitador durante o processo. Não somos mediadores entre ONGs, Estado ou a própria universidade e esses grupos, mas nessa relação podemos fazer intervenção qualificada. Mesmo os instrumentais para as oficinas vão depender da demanda do grupo. Por exemplo, na cartografia dos Xukuru, o mapa base foi um construído por eles anteriormente a partir da Terra Indígena que foi demarcada pela Funai. Já na cartografia dos times de futebol em Santo Amaro, usamos GPSpara identificar com precisão os campos e espaços dos Clubes, em Tapará havia a necessidade de uso do GPS para identificar os locais de origem e migração das famílias do grupo antes de chegarem a Tapará, mas não havia necessidade do mesmo para demarcar o território porque não era o objetivo do fascículo. 
Um dos princípios do PNCS é que a solicitação para a cartografia deveria partir do próprio grupo. No entanto, hoje percebemos que em algumas situações é preciso um estímulo, que se dá através de pesquisas anteriores, como foi o caso em Santo Amaro e entre os tapuias de Tapará. Esse formato é interessante, porém demanda muito mais tempo do que o fazer cartográfico sem a pesquisa de campo anterior.

Como uma questão mais profunda que precisa ser melhor discutida é o fato de que apesar de termos consciência de que embora a cartografia tenha um caráter "emancipatório", ela também fixa e torna estática realidades que na prática são dinâmicas e fruto de negociações. Com isso, pode criar novas relações de poder e legitimar facções, grupos e agentes. Isso não significa a inviabilidade da cartografia. Como já citado no início desse artigo, o mapa e a cartografia como um todo, sempre serviu para assegurar o poder do Estado, uma forma de domínio sobre o espaço.

O Projeto Nova Cartografia Social proporciona um outro olhar sobre o espaço, sobre o poder da técnica, da produção de conhecimento e do constructo das relações sociais apresentadas por um grupo social em forma de mapa, com todo seu potencial político, emancipatório e de subversão da lógica dominante. Sua base se dá na articulação de lutas que se constroem em torno de identidades, cujo pertencimento é resultado de um ato combinado entre pessoas, decorrente de formas de mobilização. Como destacado por Almeida ${ }^{5}$, os fatores identitários são indissociáveis de qualquer luta travada e estão subjacentes à mobilização. Diferentemente de tomá-las como fatores desintegradores, tais mobilizações não enfraquecem formas organizativas tradicionais com base em partidos políticos, sindicatos ou categorias de classe. Acatando a pluralidade de articulações políticas, o PNCS toma, no processo de construção de mapas, a centralidade das lutas que ganham forma não imediatamente perceptível e nos apresentam outras possibilidades de repertórios confrontacionais.

\section{CARTOGRAFIAS E REPERTÓRIO CONFRONTACIONAL}

A cartografia vem sendo utilizada como um mecanismo apropriado pelo Estado, para através do controle da Técnica, firmar um lugar de poder sobre a definição e classificação do mundo. No entanto, sua apropriação e relação com as dinâmicas de mobilização, negociação e confronto das ações coletivas pode nos conduzir a uma outra constatação: de que passa a constituir um elemento importante daquilo Charles Tyler chama de "repertório confrontacional" que "compreende o conjunto de formas de ação política surgidas em meio a conflitos numa dada época e que a partir de então fica à disposição dos atores sociais". (ALONSO; BOTELHO, 2012, p. 11). Mesmo as experiências relatadas não tendo um "adversário" a priori fixado, para o qual poderia estar diretamente direcionado, percebe-se que a cartografia apresenta espaços possíveis para lutas políticas.

Poderíamos dizer que tais lutas se dão em distintas esferas de ação política. Confrontos que se dão em todo o processo de construção dos mapas, daí afirmarmos que, ao invés de termos um modelo de metodologia, apresentamos princípios de intervir no mundo, de problematização da racionalidade técnica e de enfrentamento aos conflitos que se apresentam no mundo vivido. A primeira esfera diz respeito ao próprio processo de pesquisa. Não constituindo uma escola de pensamento, mas uma forma de trabalho, a elaboração dos mapas, no contexto do PNCS é um objeto de reflexão que coloca em discussão 
o que estamos fazendo e possibilita a problematização da própria etnografia. A segunda esfera diz respeito às dinâmicas internas dos grupos que protagonizam a elaboração de mapas. $\mathrm{O}$ conhecimento advindo do processo não é uma luz exterior, uma revelação, mas uma criação dos participantes que assumem lugar de sujeitos ativos na atividade do conhecer. A terceira esfera refere-se às disputas cujos mapas dão visibilidade, podendo constituir constrangimentos históricos ou demandas que se conformam na atualidade em torno dos territórios. Como aponta Ascerald (2017, p. 26.), são disputas de poder sobre os mapas ou a partir dos mapas e "realizar o seu próprio desenho é o único meio de não sofrer os efeitos indesejados de ser desenhado por outros, e sim de controlá-los".

Nesse sentido, a técnica voltada para o mapeamento se torna um assunto ou uma questão filosófica porque diz respeito ao poder de intervenção e de controle do ser humano sobre mundo e sobre si mesmo. Realizar seu próprio desenho, se apropriar da técnica, da linguagem tecnológica e refletir sobre as disputas que se dão em torno do espaço e da classificação do mundo a partir dos mapas, é um trabalho intelectual compartilhado entre pesquisadores e agentes sociais.

\section{O ADJETIVO "NOVA" E A "RACIONALIZAÇÃO SUBVERSIVA"}

Por fim, as experiências compartilhadas neste artigo possibilitam problematizarmos a elaboração de mapas e da própria etnografia que acompanha este mesmo processo. Enquanto método, a etnografia nos permite deslocar o ângulo de produção de verdades e questionar as classificações inerentes à vida social.

Com frequência, os pesquisadores e pesquisadoras do PNCS têm afirmado que o que diferencia sua prática de outras iniciativas de cartografia é a demanda dos agentes sociais e unidades de mobilização, é a autoria compartilhada dos mapas e textos a eles relacionados. Poderíamos dizer que essas são as características mais evidentes de tal prática, mas que esta, acima de tudo, se afirma-se como um trabalho intelectual que problematiza o lugar e o uso da técnica, concebendo-a como uma questão ética e política. Tal como posto por Feenberg ${ }^{6}$, partimos da convicção que o projeto tecnológico dominante na contemporaneidade contribui para o aumento da injustiça social, dado que atende unicamente aos interesses dos tecnocratas (ou, nas palavras do autor, de uma racionalidade política). Para Feenberg,as modernas formas de hegemonia estão baseadas na mediação técnica de uma variedade de atividades sociais, seja na produção, na medicina, na educação, no exército, e, por consequência, a democratização de nossa sociedade requer tanto mudanças técnicas radicais quanto mudanças políticas, uma posição controvertida.

Assim, o adjetivo"nova", do Projeto "Nova" Cartografia Social inscreve uma posição de subverter as práticas e técnicas do conhecimento cartográfico restrito aos especialistas e agentes estatais. Ainda dialogando com Feenberg, a tecnocracia, base da racionalização na nossa sociedade, responde a uma definição particular de tecnologia como um meio para obter lucro e poder. Uma compreensão mais abrangente da tecnologia sugere uma noção muito diferente de racionalização, baseada na responsabilidade da ação técnica quanto aos contextos humanos e naturais. É isso que o autor denomina de "racionalização subversiva”, porque requer avanços tecnológicos que só podem ocorrer em oposição à hegemonia dominante, o que representa uma alternativa à celebração contínua da tecnocracia triunfante. 
Subverter a ordem de quem faz, como faz e das formas de uso dos mapas resultantes das experiências do PNCS tem possibilitado este, com a significativa produção de fascículos, boletins e outras publicações não muito convencionais, já se afirmar como uma tradição transformadora, constituindo-se "num capital, numa grande força para a reivindicação por direitos e por melhorias de vida por parte de grupos sociais dominados". (LOPES, 2016, p. 28).

\section{NOTAS}

${ }^{1}$ As pesquisas que originaram esse artigo intitulam-se: "Práticas e Espaços Sociais: Uma cartografia dos espaços de mobilização do bairro de Santo Amaro, Recife-PE", e ocorreu entre 2012 e 2014, com financiamento do CNPq; e "Práticas, espaços e emergência étnica: Uma cartografia dos povos indígenas no Rio Grande do Norte", também com financiamento do CNPq.

${ }^{2} \mathrm{O}$ PNCS inicialmente teve como foco a cartografia social dos povos e comunidades tradicionais da Amazônia, cuja sigla era PNCSA. O mesmo se expandiu para o Brasil como um todo e suas regiões específicas.

${ }^{3}$ Os fascículos são os resultados das oficinas temáticas e de mapas. São escritos pelos próprios oficineiros e, ao ficarem prontos, são distribuídos à comunidade cartografada para serem usados como instrumento do grupo em suas pautas de reivindicações. Os mesmos podem ser conferidos no site do Projeto Nova cartografia social $<$ http://novacartografiasocial.com>.

${ }^{4}$ A identificação dos Aglomerados Subnormais é feita com base nos seguintes critérios: a) Ocupação ilegal da terra, ou seja, construção em terrenos de propriedade alheia (pública ou particular) no momento atual ou em período recente (obtenção do título de propriedade do terreno há dez anos ou menos); e b) Possuir pelo menos uma das seguintes características: 1- urbanização fora dos padrões vigentes - refletido por vias de circulação estreitas e de alinhamento irregular, lotes de tamanhos e formas desiguais e construções não regularizadas por órgãos públicos; 2- precariedade de serviços públicos essenciais.

${ }^{5}$ Palestra proferida no I Encontro de Pesquisadores e Agentes Sociais do Projeto Brasil Central, em setembro de 2017, Campus da UNEB, Juazeiro/BA.

${ }^{6}$ Andrew Feenberg, filósofo norteamericano, tem se destacado com a publicação de uma série de trabalhos ligados à filosofia da tecnologia, dentre os quais Questioning technology (1999), onde argumenta que o desenho tecnológico é central para as estruturas sociopolíticas democráticas, mostrando como a tecnologia se transforma no âmbito em que se desenrola a vida cotidiana, Transforming technology (2002), no qual revê e atualiza sua «teoria crítica da tecnologia», reexaminando as relações entre tecnologia, racionalidade e sociedade.

\section{REFERÊNCIAS}

ALMEIDA, Alfredo Wagner Berno de. Carajás: a guerra dos mapas. Belém: Editora Falangola, 1993.

ALMEIDA, Alfredo Wagner Berno de. Os Quilombos e as novas etnias. Manaus: UEA Edições, 2011.

ALONSO, Angela; BOTELHO, André. Repertórios de ação coletiva e confrontos políticos: entrevista com sidneytarrow. Sociol. Antropol., Rio de Janeiro, v. 2, n. 3, p. 11-19, June 2012. Disponível em: <http://www.scielo.br/scielo. php?script=sci arttext\&pid=S2238-38752012000300011\&lng=en\&nrm=iso $>$. $<$ http://dx.doi.org/10.1590/2238-38752012v231>. Acesso em: 31 Mar. 2018. . ASCERALD, Henri. O lugar e as possibilidades da política: sentidos da cartografia social. Rio de Janeiro/São Luís: Casa 8, 2017. 
ASCERALD, Henri; COLI, Luiz Régis. Disputas territoriais e disputas cartográficas. In: Henri ASCERALD; Luiz Régis. COLI, (Orgs.). Cartografias sociais e território. Rio de Janeiro: IPPUR/UFRJ, 2008.

BARCELLOS, Jorge. Territórios do cotidiano: uma introdução a uma abordagem teórico contemporânea. In: Zilá MESQUITA; Carlos BRANDÃO (Orgs.). Territórios do cotidiano: uma introdução a novos olhares e experiências. Porto Alegre/ Santa Cruz do Sul: Editora Universidade/UFRGS/UNISC, 1995.

BOURDIN, Alain. A questão local. Rio de Janeiro: Editora DP\&A, 2001.

BRAGA, Ísis; FIALHO, Vânia; PIRES, Maria Jaidene. Regularização do espaço vivo e vivido: a questão fundiária do bairro de Santo Amaro. QuadernidiThule. Perúgia: Circolo Amerindiano, 2013.

CALDEIRA, Teresa Pires do Rio. Cidade de Muros: crime, segregação e cidadania em São Paulo. São Paulo: Editora 34/ EDUSP, 2000.

CANEVACCI, Massimo. A cidade polifônica: ensaio sobre a antropologia da comunicação urbana. São Paulo: Studio Nobel, 2004. (Coleção cidade aberta)

FEENBERG, Andrew. Racionalização Subversiva: Tecnologia, Poder e Democracia. GONÇALVES, Anthony (trad.). [1992]. Disponível em: <https:// www.sfu.ca/ andrewf/books/Portug_Racionalizacao_Subversiva_Tecnologia_Poder_Democracia.pdf). Acesso em: 18 dez. 2018.

FIALHO, Vânia. Tensões e dinâmicas territoriais: povos e comunidades tradicionais no contexto do desenvolvimento de Pernambuco. Raizes (UFPB), v. 31, p. 111, 2011. (Dossiê: Povos e comunidades tradicionais).

FREITAG, Barbara. Teorias da Cidade. Campinas: Papirus, 2012.

HABERMAS, Jüngen. A inclusão do outro: estudos de teoria política. São Paulo: Edições Loyola, 2002.

LOPES, José Sérgio Leite. Memória e transformação social. Rio de Janeiro/ São Luís: casa 8, 2016.

MARICONDA, Pablo Rubén; MOLINA, Fernando Tula. Entrevista com Andrew Feenberg. Sci. stud., São Paulo, v. 7, n. 1, p. 165-171, Mar. 2009. Available from $<\mathrm{http}$ ://www.scielo.br/scielo.php?script=sci_arttext\&pid=S1678-31662009000100009\&lng=en\&nrm=iso $>.<\mathrm{http} / / / \mathrm{dx}$. doi. org/10.1590/S1678-31662009000100009>. Acesso em: 31 mar. 2018

MELUCCI Alberto. A invenção do presente.Petrópolis Editora: Vozes, 2001.

MESQUITA Zilá, 1995, Do território à consciência territorial, In: MESQUITA Zilá M; BRANDÃO Carlos Rodrigues (Orgs.), Territórios do cotidiano, Ed. Universidade/UFRGS/ UNISC, Porto Alegre.

NEDER, Ricardo T. A teoria crítica de Andrew Feenberg: racionalização democrática, poder e tecnologia. Brasília: Observatório do Movimento Social na América Latina/CDS/UnB/CAPES, 2010.

OLIVEIRA, Jelson Roberto de. A técnica como poder e o poder da técnica: entre Hans Jonas e Andrew Feenberg. Revista de Filosofia Aurora, [S.1.], v. 27, n. 40, p. 143-166, abr. 2017. ISSN 1980-5934. Disponível em: <https://periodicos. pucpr.br/index.php/aurora/article/view/568/502>. Acesso em: 31 mar. 2018.

PREFEITURA DA CIDADE DO RECIFE, 2005, Atlas do Desenvolvimento Humano no Recife.

SÁ, Alcindo J; CRUZ, Luciana. Medo Urbano e suas novas formas geográficas. Recife, Universitária, 2011

SCOTT, Russel Parry. Descaso planejado: uma interpretação de projetos de barragem a partir da experiência da UHE Itaparica no Rio São Francisco. In: ZHOURI, Andréa. Desenvolvimento, reconhecimento de direitos e conflitos territoriais. Brasília: ABA, 2012. 
SOUZA, Marcelo Lopes. Os conceitos fundamentais da pesquisa sócio-espacial. Rio de Janeiro: Bertrand Brasil, 2013.

SOUZA, Maria Ângela de Almeida. Avanço e arrefecimento do processo de regularização fundiária dos assentamentos populares do Recife. Trabalho apresentado no III Congresso Brasileiro de Direito Urbanistico; Grupo 2: Direito à moradia: Segurança da Posse, Urbanização, Financiamento e Acesso à terra.s/d.

VIANNA Aurélio. O reencantamento da cartografia, "Le Mondo Diplomatique”, Jun, 2009.

VILLELA, Danielle. Nordeste cresce acima da média do País. O Estado de S. Paulo, São Paulo, 23, setembro. 2013. Economia. 